\title{
Barriers to Improvements in Energy Efficiency'
}

\author{
Amulya K.N. Reddy
}

October 1991

This paper was presented at the "International Workshop on Reducing Carbon Emissions from the Developing World: Assessment of Benefits, Costs and Barriers," Lawrence Berkeley Laboratory, Berkeley, California, USA, October 4-6, 1990, and revised subsequently in the light of discussions at the workshop and comments by colleagues. The work was supported by the U.S. Environmental Protection Agency, Office of Policy Analysis, Division of Global Climate Change through the U.S. Department of Energy Contract No. DE-AC03-76SF00098. 


\begin{abstract}
Patterns of energy consumption are shaped by the behaviour of a large number of actors, each of whom has to make many decisions relating to energy-using activities. Thus, the implementation of energy-efficiency improvements involves actors operating at various levels. In this paper, the following actors are considered: energy consumers (individuals, households, firms, farms, factories, etc.), manufacturers and providers of end-use equipment, producers and distributors of energy carriers, actual and potential cogenerators, local/national financial institutions, governments/countries and funding/aid agencies of international and multilateral organizations and of industrialized countries.
\end{abstract}

To promote energy-efficiency improvements, actions may be required at one or more levels -- from the lowest level of the consumer (residential, commercial, industrial, etc.) through the highest level of the global agencies. But barriers to the implementation of energy-efficiency improvements exist or can arise at all these levels.

At the level of energy consumers, the barriers to energy-efficiency improvements are due to the ignorant, the poor and/or first-cost-sensitive, the indifferent, the helpless, the uncertain and the inheritors of inefficiency. In the case of manufacturers and providers of end-use equipment, barriers arise due to the efficiency-blind and the operating-cost-blind respectively. The barriers at the level of producers and distributors of energy carriers are due to the supplyobsessed, the centralization-biased and the supply-monopolists. Actual and potential cogenerators can be cogeneration-blind. Local/national financial institutions can be supplybiased, unfair and hold anti-innovation attitudes. In the case of governments or countries, barriers arise from governments/countries that are uninterested, short of skills, without adequate training facilities, without access to hardware and software and short of capital (particularly in the case of infrastructure-poor countries). Other governmental barriers involve the salespromoting regulator, the powerless energy-efficiency agency, the cost-blind price-fixer, the fragmented decision maker, the large-is-impressive syndrome and the large-is-lucrative approach. Finally, at the level of international, multilateral and industrialized country funding/aid agencies, there are barriers due to the exporters of inefficient technology, the supply-biased, the antiinnovation attitude, the large-is-convenient funder, the project-mode sponsors and the selfreliance underminers (alias the dependence-perpetuators).

Taking up each one of these barriers in turn, the paper discusses specific measures that can contribute to overcoming the barriers. However, a one-barrier-one-measure approach must be avoided. Single barriers may in fact involve several sub-barriers. Also, combinations of measures are much more effective in overcoming barriers. In particular, combinations of measures that simultaneously overcome several barriers are most successful.

A frequently implemented package consists of a combination of fiscal incentives, price controls, technical research and development (R\&D), publicity and educational measures and legislation encompassing the public and private sectors, individuals and organizations. From this point of view, energy service companies are also combination packages, because they are 
"single-window" agencies for implementing all components of energy-efficiency programmes -providing information, assessing requirements, financing, organizing contractors, etc.

Combinations of measures are also necessary at the strategic level. Least-cost planning is an example of such a combination. Comprehensive strategies are also required to improve the fuel efficiency of vehicles using petroleum products.

Since many of the barriers result in an imperfect market for efficiency improvements, price mechanisms alone will not work and market forces on their own will not achieve the potenitial for energy efficiency. There has to be an emphasis on policy-assisted, market-oriented mechanisms for promoting energy efficiency.

This paper emphasizes the importance of having a grander vision than energy-efficiency improvements. Promoting innovation rather than energy efficiency per se is likely to be an especially effective way of improving efficiency (as long as energy is priced correctly). Minimizing total production costs (and thus encouraging new technology) will often lead to lower energy use than minimizing life-cycle energy costs (which could prolong the life of obsolete technology). Such a stress on innovation necessarily means an emphasis on research and development.

Thus, the paper discusses the typology of barriers, explores their origin and suggests measures that, by themselves or in combination with other measures, will overcome these barriers. Since most of the barriers dealt with can be found in the "barriers" literature, any originality in the paper lies in its systematic organization, synoptic view and holistic treatment of this issue. Of course, the scheme can be expanded and improved. In that sense, this paper is intended to initiate a comprehensive treatment of barriers, their origins and the measures that contribute to overcoming them. Hopefully, such a treatment will facilitate the implementation of energy-efficiency improvements involving a wide diversity of ever-changing energy end uses and consumer preferences. 


\section{INTRODUCTION}

There is a growing appreciation of the role that improvements in energy efficiency can play in bridging the gap between energy supply and demand. At the same time, there is an increasing realization that these improvements are not penetrating society as rapidly as their potential would suggest. Attention, therefore, is being turned to the factors determining the implementation, acceptance and spread of these improvements. ${ }^{2}$

A few clarifications regarding terminology and scope are in order at this stage. In this paper, the term "energy-efficiency improvement" will be used synonymously with "conservation." At first sight, this may not appear justified, because a reduction in energy consumption not only can be brought about by an improvement in the efficiency of a device or process (e.g., an increase in the fuel efficiency of automobiles), but also by changes in the way the device is utilized (e.g., car pooling so that the number of passengers per car is increased). When the term "improvement" is restricted in applicability to a device or a process, then energyefficiency improvements are a sub-set of conservation measures.

If, however, the improvement under discussion is that of the energy system as a whole or part thereof, then "software" changes in the way devices and processes are used also come under the scope of the term "energy-efficiency improvements," which thus becomes synonymous with "conservation." The term "energy-efficiency improvements" is used here in this extended sense to include any measure that results in the delivery of any energy service with a reduction in energy consumption. Thus, carrier substitution or fuel-switching measures that lead to reductions in energy demand also become examples of energy-efficiency improvements; hence, decentralized and/or renewable sources come within the purview of the term "energy-efficiency improvements." The potential for energy savings through cogeneration (the combined production of heat and electricity) provides an obvious reason why decentralized sources must be considered under the rubric of energy efficiency.

Further the term "energy-efficiency improvements" is not restricted to "retrofitting" (i.e., improving the efficiency of devices and processes already in place and operation), to conventional technologies and to the residential sector. It includes an emphasis on energy efficiency in new plants and equipment, new technology and the energy-intensive sub-sectors of industry.

Patterns of energy consumption are shaped by the behaviour of a large number of actors, each of whom has to make many decisions reiating to major energy-using activities. Thus, the implementation of energy-efficiency improvements involves a number of actors operating at various levels. In particular, the following actors are involved:

- energy consumers (individuals, households, firms, farms, factories, etc.)

0 manufacturers and providers of end-use equipment

0 producers and distributors of energy carriers

0 actual and potential cogenerators 
- local/national financial institutions

- governments and/or countries

- funding/aid agencies of international and multilateral organizations and of industrialized countries.

Thus, action may be required at one or more levels - from the lowest level of the consumer (residential, commercial, industrial, etc.) through the highest level of global agencies. But, barriers to the implementation of energy-efficiency improvements exist or can arise at all these levels.

An overview of the various barriers, their origins and the measures that can contribute to overcoming them is presented in Table 1. However, a note of warning must be sounded here. The tabular presentation may give the impression that the overcoming of barriers is simply a matter of identifying a specific barrier and implementing the corresponding measure for overcoming the barrier. However, reality is far more complicated than the tabular scheme might suggest. First, barriers may not come singly; an actual situation can involve many barriers operating simultaneously. Second, even if there is a single barrier, the corresponding measure may only be a necessary condition for overcoming it; it may not be a sufficient condition, because other measures may have to be resorted to in addition. So, the table must not lead to a naive one-barrier-one-measure approach. After a barrier has been identified, it is a good precaution to ask two questions: (1) Is this the only barrier? and (2) Is the corresponding measure a necessary and sufficient condition to overcome the barrier?

The purpose of this paper is to attempt to create a typology of the possible barriers, to explore the origin of these barriers and to suggest measures that by themselves or in combination with other measures will overcome these barriers. Since most of the barriers dealt with can be found in the "barriers" literature, any originality in the paper lies in its systematic organization, synoptic view and holistic treatment of this issue. Of course, the scheme can be expanded and improved. In that sense, this paper is intrnded to initiate a comprehensive treatment of barriers, their origins and the measures that contribute to overcoming them. Hopefully, such a treatment will facilitate the implementation of energy-efficiency improvements involving a wide diversity of every-changing energy end uses and consumer preferences.

\section{ENERGY CONSUMERS}

A. The Ignorant: The implementation of energy-efficiency improvements requires the concurrence, support and participation of the ultimate consumer of energy (in the residentiai, transport, industrial, agricultural or commercial sectors). In turn, this involvernent depends upon the consumer knowing about the energy technology, being aware of the efficiency improvements that are possible and understanding the costs and benefits of the options. However, many consumers -- not only individuals and households but also enterprises (firms, farms, factories, etc.) -- are quite ignorant of the possibilities for efficiency improvement and are unaware of the cost-effectiveress of conservation measures. And, the situation is aggravated 
by the fact that the field of energy-efficiency improvements is characterized by very rapid technological change.

The obvious way to overcome this barrier of ignorance is to provide information in various ways (door-to-door canvassing, leaflets through the mail, newspapers, magazines, radio and television). Demonstrations also can play a key role. And, of course, the training of consumers is a powerful way of educating them with regard to the advantages of efficiency improvements. In this process, it is not only the quantity of information that matters; the quality of information and the effectiveness of the communication also matter. ${ }^{3}$

Information, education and training are particularly important for energy-intensive industries. In Japan, for instance, such industries come under the classification of "designated factories," which are required oy law to have up to four trained energy managers with specific responsibilities laid down by law. ${ }^{4}$ This network of highly trained energy managers ensures high standards of energy efficiency in industry.

Empirical studies have shown, however, that simply improving the supply of information to consumers is not sufficient to achieve energy conservation goals. Incentives may be more important than information. Nevertheless, the effective supply of relevant information of the right quality and the education and training of the consumer are important contributions to overcoming the barrier posed by the ignorant.

B. The Poor and/or First-cost-sensitive: Even if a consumer is fully knowledgeable about the net benefits accruing from an efficiency improvement, it does not follow that the consumer will make the necessary investment in the associated energy device or equipment. This is because quite often, the greater the efficiency of an energy device or equipment, the higher its initial cost. In other words, efficient devices and equipment often cost more than inefficient versions. So it is natural for the energy consumer to ask: do the energy savings and other benefits justify the increased investment in the efficiency improvement?

The answer to this question depends upon whether the consumer is prepared to invest capital resources now in order to reap the regular benefits of lower energy bills in the future. Will the consumer minimize life-cycle costs instead of minirizing first costs? Is the consumer prepared to postpone current consumption for the sake of future benefits? The index of this preparedness is the consumer discount rate (CDR) which is approximately equal ${ }^{6}$ to the annual return or benefit expected for a long period (say 10 years) on an initial outlay of $\$ 100$. For example, if the CDR is $60 \%$, it means that the consumer will be prepared to make an initial investment of $\$ 100$ only if an annual benefit of at least $\$ 60$ can be obtained for the next 10 years.

Another way of describing the situation is in terms of the so-called pay-back period, which is the time required to recoup an energy investment through the monetary savings from the energy bill. The high CDRs are a reflection of the fact that energy consumers insist on relatively short pay-back times (about two years) whereas energy producers can tolerate 
relatively longer pay-back times (about eight years or more). So, there is a pay-back gap; ${ }^{7}$ the energy-efficiency investments that producers would consider seriously would not even be looked at by energy consumers.

When empirically determined CDRs are compared with interest rates from banks, it is found that the CDRs are very much higher than commercial rates (on the order of $10 \%$ ). Obviously, the CDR is a reflection of the amount of capital available to the consumer; the more disposable cash a consumer has, the more prepared the consumer will be to invest this cash now to earn future benefits.

One would expect, therefore, that as the income of the consumer increases, the CDR used for investment decisions will decrease, and conversely, the poorer a consumer, the less the likelihood of the consumer being prepared to sacrifice scarce capital on energy-efficient devices and equipment, notwithstanding the energy savings and other advantages normally accruing from the efficiency improvement. ${ }^{8}$

In fact, a recent study carried out in the South Indian metropolis of Bangalore shows that as the consumer's income decreases, the CDR rises exponentially. Further, surveys of consumers indicate that the CDR for residential electricity consumers with an average income of $\$ 16.60$ per month per capita is in the range of about $60 \%$.

With this information, consider a specific efficiency improvement such as the replacement of a $60 \mathrm{~W}$ incandescent bulb with a $15 \mathrm{~W}$ compact fluorescent lamp. The internal rate of retum (IRR) for this replacement is that value of the interest rate at which the present value of all the energy savings due to the efficiency improvement is exactly equal to the extra initial cost incurred by the measure. It is found that the IRR for the replacement is only about $16.5 \%$ whereas typical residential electricity consumers are unlikely to make capital investments unless the return is about $60 \%$. Obviously, it is very unlikely that such consumers will make the investment in compact fluorescent lamps even if these lamps consume only one-quarter of the energy.

Though poverty invariably leads to high consumer discount rates, it cannot be concluded that only the poor use high discount rates -- the ignorant, the indifferent and the helpless may also tend to minimize first costs rather than life-cycle costs.

If this first-cost sensitivity of the consumer is to be overcome, the IRR must be increased so that it exceeds the CDR. The IRR is approximately given by the ratio $\left[\left(\Delta E^{*} P\right) / \Delta I_{a}\right]$ where $\Delta E$ is the energy savings achieved by replacing an incandescent bulb (IB) with a compact fluorescent lamp (CFL), $P$, the electricity price and $\Delta I_{n}$, the difference in the initial costs. If even a part of the down-payment $\Delta \mathrm{I}$, is converted into installments to be paid out of the savings, then the denominator is decreased so that the effective IRR is increased.

Thus, the way to make efficiency improvements (for example, the replacement of IBs with CFLs) affordable even to the poor and/or first-cost-sensitive is to convert the initial down- 
payment into a payments stream that coincides in time with the savings stream. It is even better if the payments stream is financed out of the savings stream. This situation can be achieved by a loan being advanced for the efficient device or equipment and the principal being recovered with interest along with energy payments, or by the utility leasing the efficient device or equipment to the consumer who then pays the regular leasing charges along with the energy bills. Thus, innovative financing involving the conversion of first costs into operating costs is a crucial method of helping to overcome the barrier posed by the poor and/or first-cost-sensitive.

C. The Indifferent: The third type of barrier involves energy consumers who are indifferent to efficiency improvements even though they are fully knowledgeable about the net benefits accruing from an efficiency improvement and are in a position to afford the first costs associated with the device or equipment. This attitude can be due to the fact that consumer decisions relating to purchases of energy-using equipment are based upon a number of factors of which the cost of energy is just one, and often not a very important one at that. More importantly, the indifference to energy efficiency may stem from the fact that to these consumers their energy costs are not significant enough (relative to their total expenditures) to motivate them to implement the efficiency improvement even though the energy savings from this efficiency improvement may be extremely important to society at large.

A clear-cut example of this phenomenon has been discussed by von Hippel and Levi ${ }^{10}$ in connection with the running costs of automobiles in the U.S. They showed that there is initially a significant decrease in the running costs with improvements in fuel efficiency, following which major increases in fuel efficiency only lead to trivial reductions in the costs. In this "plateau of indifference," the cost reductions are not attractive enough to justify the extra investments necessary to achieve increases in fuel efficiency even though the associated savings of fuel are of enormous benefit to society.

Such situations are quite common in developing countries, particularly due to the unrealistic pricing of energy carriers. An obvious example is the case of irrigation pumpsets in India for which the tariffs are so ridiculously low that the farmer has no incentive at all to be frugal in the use of electricity.

In such situations, intervention by the government is imperative. Apart from realistic pricing (discussed under Section VIII. C.), the government can also promote energy savings by means of regulations covering those appliances (boilers, furnaces, pumps, lights, etc.) that are primarily responsible for poor energy efficiencies. For instance, the regulations could be implemented through manufacturers by means of standards governing the efficiencies of appliances manufactured by them.

It is also necessary to generate consumer pressure and market demand for efficient appliances. This can be done by making it obligatory for manufacturers to label all these appliances so that their energy performance is evident to all the prospective purchasers of the appliances and becomes a factor in their decision making. But government intervention in the form of labelling may not be sufficient to overcome the indifference of consumers. Thus, in the 
U.S., despite the Environmental Protection Agency's regulations necessitating the labelling of cars with their fuel efficiency performance, the indifference of consumers still persists.

In this context, the experience of the state of Kamataka in South India showed that power cuts had the unforseen result of bringing about energy savings. ${ }^{11}$ The implication is that a type of rationing of energy can induce conservation measures. Of course, the restrictions have to be of a small enough magnitude to permit the main productive activity of the consumer to continue in spite of the shortage. In the case of electricity, for instance, most consumers can easily tackle 10-15\% power cuts with simple housekeeping measures (e.g., turning off unnecessary lights and fans, improving mechanical couplings, avoiding wastage, etc.). This efficiency improvement, induced by restrictions, is an important instrument even though it is relatively unknown and little discussed in the industrialized market economies.

Thus, government intervention based on supplementary mechanisms such as regulations, standards, labels, restrictions in supply, etc. implemented singly or in combination, is a necessary condition for surmounting the barrier arising from the indifference of consumers.

D. The Helpless: There is also the class of consumers who are knowledgeable, who can afford the efficiency improvement and who are motivated but, nevertheless, are completely helpless in the face of all the problems that must be tackled in identifying, procuring, installing, operating and maintaining the associated devices and equipment.

In contrast, it is very easy for a consumer to purchase specified quantities of conventional energy carriers such as oil or electricity. Well-tested economic systems exist for making such transitions; the quantities exchanged are easy to measure; and both producers and consumers understand the values of the commodities involveu.

This is not the case for investments in energy savings. Compared to the mature energy supply industries, the infant efficiency improvement industry is in the initial stages of development and is quite often limping with government support, subsidies, etc. This invariably means that there is a great deal of paperwork to secure the requisite credit, negotiate with the suppliers/erectors of the improved devices or equipment and get them installed. The issue can be understood quite clearly by comparing the difficulty faced by a homeowner in getting a solar water heater installed on his roof with the ease with which an electric water-heating boiler can be obtained by simply walking into a store and making a payment.

It looks as if an implementation gap $^{12}$ or barrier has to be surmounted. The consuiner must have a great deal of know-how and take a great deal of effort to identify, procure, install and maintain devices and equipment that improve efficiency. (Of course, the energy savings must be above a certain threshold to warrant the additional effort to secure the energy-efficiency improvements.) Such a situation will prevail until the consumer can obtain total packages of hardware plus software (the latter being all the instructions and knowledge to run the hardware). In tum, this means that an efficiency improvement industry must be established and developed to provide these packages. 
Thus, to overcome the barrier of the helpless consumer, it is necessary that an efficiency improvement industry must be nurtured to provide consumers with the know-how in the form of total hardware plus software packages.

E. The Uncertain: The costs and benefits of energy-efficiency improvements depend very much on the current and future prices of energy carriers and devices. And, if there is uncertainty about these prices, then the decision making becomes problematic. Under these conditions, which are aggravated by economic instability, consumers tend either to postpone the decision or to play it safe and avoid investments. This results in the barrier of the uncertain consumer.

Thus, the barrier of the consumer who is uncertain about the future prices of energy can be addressed by stabilizing or slowly changing the prices over the long term and/or financing investments and recovery at a guaranteed rate.

F. The Inheritors of Inefficiency: Finally, there are the consumers who qualify on all counts - knowledge, capital, motivation, know-how or access to know-how -- but they are in the unfortunate situation of having inherited inefficient devices or equipment. They are victims of indirect purchase decisions. The most common example of this situation is that of tenants who rent a house that is energy inefficient (from the point of view of heating, cooling or lighting) or have to use facilities that are inefficient.

The origin of this problem is split burdens: the burden of capital investments falls on the builder (or landilord) and that of paying the energy bills rests with the homeowner (or tenant). With such a difference in burdens, there is a fundamental contradiction in incentives -- the builder (or landlord) has an incentive to minimize capital costs by purchasing the cheapest equipment (which is often the most energy inefficient) and the home owner (or tenant) has the opposite incentive, to minimize operating costs by having the most energy-efficient equipment. What is required, however, is an incentive system in which the total life-cycle costs (which include both the initial capital costs and the operating costs over the entire life of the equipment) are minimized. In the first place, the tenant can articulate his market demand by scrutinizing the energy efficiency of the building and exerting his preference for low energy-consuming buildings. But, this means that prospective tenants must know the energy efficiency of buildings. In other words, buildings must be labelled so that their energy efficiencies are specified. Pressures can also be applied on the builder or landlord, but these are discussed in Section IV. A.

Thus, the barrier of inherited inefficiency can be partly overcome by labelling equipment with energy performance data and thereby arming consumers with the knowledge of how to exert pressure on the equipment providers.

\section{MANUFACTURERS OF END-USE EQUIPMENT}

A. The Efficiency-Blind: Usually, the sales of end-use equipment depend far more on the first cost of equipment than on its energy efficiency. In fact, since quite often lower first cost means 
lower efficiency, sales may actually decrease with efficiency improvements. In such a situation, the motivation of manufacturers to improve the efficiency of their products is often secondary to other design changes. Also, the marketing and sales strategies of manufacturers and retailers may emphasize sales of less efficient equipment. Thus, the first-cost sensitivity of consumers is responded to by manufacturers, distributors and retailers with offers of low first-cost devices and equipment with low efficiencies. As a result, energy-efficient equipment just may not be available and consumers are made victims of forced purchase decisions. Or, energy efficiency is coupled with other expensive features and made available only in the "gold-plated" or expensive brands.

Such an environment encourages efficiency-blind producers of end-use devices and equipment. Part of the problem is that (unless special measures have been implemented) neither the manufacturer nor the seller of end-use devices and equipment are obliged either by market pressure or by law to reveal the energy performance of devices and equipment. Thus, an Indian consumer cannot know which of a number of electric water heaters, for example, has the lowest energy consumption.

The barrier to efficiency improvements arising from efficiency-blind manufacturers can be overcome partly by government intervention enforcing efficiency standards and the labelling of end-use devices and equipment so that the prospective buyer can take the energy consumption into account before the purchase of the equipment. The consumer will be further motivated to ascertain the energy efficiency of equipment if the financing of this equipment (e.g.e. the interest rate) is tied to the energy efficiency.

It is obvious that the energy-efficiency standards necessary for appliances to achieve savings must be updated at regular intervals (in order to keep pace with technical improvements) if they are to remain effective. Also, "near-term measures to promote energy efficiency through the use of existing energy-efficient technologies should be complemented by measures that encourage manufacturers to routinely make energy efficiency a design criterion of the innovative process. ${ }^{13}$

\section{PROVIDERS OF END-USE EQUIPMENT}

A. The Operating-costs-blind: Mention has been made already of situations where the provider of end-use equipment minimizes the capital cost of the equipment irrespective of the consequences of that decision on the energy consumer, who has to pay for the operating costs. Buildings are an example of this situation. Apart from inducing the consumer to exert market pressure in favour of efficiency improvements, government intervention to influence the providers of equipment are also necessary. For instance, in the case of buildings, advantage can be taken of the fact that a building project involves a number of steps of which two lend themselves easily to energy-efficiency measures: (1) approval of building designs and (2) securing finance usually in the form of a loan. Intervention in favour of energy efficiency is possible at both these stages -- building codes can be enacted that stress energy efficiency, and the loans can take into account life-cycle costs of equipment, not merely the initial costs. 
Thus, legal approvals and financing that depend upon energy efficiency and standards can contribute to surmounting the barrier of equipment providers who turn a blind eye to operating costs.

\section{PRODUCERS AND DISTRIBUTORS OF ENERGY CARRIERS}

A. The Supply-obsessed: Invariably, the producers and distributors of energy carriers (electricity, coal, petroleum products) are so obsessed with the supply of their energy carriers that they devote little attention to the utilization of these carriers. In particular, they do not bother with the efficiency with which their energy carriers are used. This supply-obsession of the producers and distributors of energy carriers is a barrier to the marketing of energyefficiency improvements.

The obsession of electrical utilities with supplies is not without a rational basis. The thinking of utilities often runs thus: "Conservation is not a natural business niche for utilities. Conservation involves equipment we do not make, which is installed on property we do not own and requires kinds of work where we have no natural advantage. Conservation increases the cost of the commodity."14 More importantly, most utilities are regulated and traditional regulatory rate-making formulas are such that profits are proportional to sales. ${ }^{15}$

In the U.S., for instance, "...the rate-making process has the following unintended, but nevertheless perverse, incentives": ${ }^{16}$

(1) Electricity profits increase with every additional $\mathrm{kWh}$ sold.

(2) Electricity profits decrease with every additional $\mathrm{kWh}$ saved.

(3) The only financial incentive to pursue cost-effective conservation is the risk that unsatisfied regulators may disallow costs.

In this scheme of things, if an electric utility company makes investments in demand-side programmes, it not only loses revenues due to decreased sales, but, in addition, it loses returns on its investments in demand reduction.

An extreme example of this disincentive is when generation and distribution are handled by separate companies, ${ }^{17}$ in which case the generator cannot implement demand-side measures even if they are cheaper than generation, and the distributor can only lose if sales are lowered by efficiency improvements.

The problem is aggravated by the fact that the marketing of efficiency improvements is inherently more complicated than the marketing of energy supplies and conventional end-use technologies. One must be concerned not just with producing new energy-efficient devices but with the full spectrum of relatively novel marketing problems:

(1) diagnosis of the individual consumer's needs for obtaining energy services in the most 
cost-effective manner and, thereby, identification of the technical changes that are necessary;

(2) consumer education as to the necessity of making these changes -- a task made difficult because the expected savings are often ambiguous;

(3) the financing of any new devices or contractor work that may be required;

(4) after-sales servicing;

(5) monitoring of performance in the field to ascertain actual savings, with feedback that can be used to modify energy saving strategies.

Efforts should address all these aspects of the marketing of energy efficiency, i.e., the efforts should be concerned not just with the production of the hardware involved but with all the necessary supporting "software" as well.

The provicers and distributors of energy crriers (the electricity boards, coal and oil companies and gas utilities) are good candidates for marketing the services required for such an effort. Already a number of the more progressive utilities in the industrialized countries have initiated programs on energy conservatio.. that include:

(1) providing advice on investments in energy efficiency;

(2) offering to arrange for contractors to carry out such work;

(3) financing such investments with low or zero interest loans; and

(4) providing rebates to consumers for the purchase of energy-efficient appliances and/or to appliance dealers for promoting sales of more efficient equipment.

Accustomed to handling large quantities of capital, the producers and distributors of energy carriers are well positioned to direct some of these resources to investments on efficiency improvements. Also, they have an administrative structure for channeling the capital to essentially all househoids and businesses. Moreover, the billing systems of the suppliers of energy carriers offer the opportunity for customers to invest in devices for improving efficiency with loans from the suppliers and to pay back these loans through their energy bills.

If the charter of the producers and distributors of energy carriers is restricted to the supply of carriers, these actors cannot undertake the comprehensive marketing of efficiency improvements. What is required, therefore, is a conversion of energy supply agencies into energy service companies, that is, companies that market energy services (heating, cooling, lighting, etc.) in much the same way they market energy carriers today. Energy suppliers must diversify in this direction of energy services. Then, they would come to play a role originally envisioned for them by Thomas Edison when he invented the incandescent bulb; he proposed that utilities sell illumination, thereby giving them a financial interest to provide this illumination in the most cosi-effective way.

Very often, this issue of charter is a matter of perception rather than of law. In Karnataka, for instance, senior officials of the Karnataka Electricity Board have asserted that the board cannot sell or lease energy-efficient devices and recover the costs through their billing. 
system. In fact, The Electricity (Supply) Act. 1948 (as amended by Acts No. 16 and 20 of 1983) reads thus:

\section{Power to Board to engage in certain undertakings}

(1) The Board may, in accordance with any regulations made in this behalf, manufacture, purchase, sell or let on hire on the execution of a hire-purchase agreement or otherwise, any electric machinery, ... or apparatus for lighting, heating, cooling, or motive power or for any other purpose for which electricity can or may be used, .... and may install, connect, repair, maintain or remove such ... apparatus, .... and in respect thereof demand and take such remuneration or rents and charges and make such terms and conditions as it deems fit.

(2) The Board may ... generally do all things including advertising, incidental to the sale and hire of such .... apparatus ...

(3) The Board shall show separately in its accounts moneys received and expended by it in connection with any undertakings in which it engages under this section.

In Karnataka, therefore, there is no legal barrier to electrical utilities functioning as vendors of energy services.

In some instances, the producers and distributors of energy carriers may be unwilling to create and implement programmes on electricity conservation. For example, a board may have sufficient generating capacity that it sees no need to help its customers use energy more efficiently. In such circumstances, the government could stimulate the creation of independent new companies that would market energy-efficiency improvements (e.g., by making loans or grant assistance available to customers).

Thus, a change in the charter of the producers, from suppliers of carriers to vendors of energy services, and/or a growth in independent energy service companies can contribute to overcoming the barrier of supply-obsessed producers of energy carriers and the barrier of a nonexistent or weak industry for marketing energy services.

B. The Centralization-biased: As if the obsession with supplies is not a sufficient barrier to energy efficiency, the producers of energy carriers concentrate exclusively on centralized supplies. This bias towards centralization prevents any attention being paid to decentralized sources of energy in general and biomass sources in particular. A barrier is therefore generated as a result of which there is virtually total neglect of improvements in decentralized generation and in the efficiency with which such sources are utilized. In the context of this bias, any attempt at supply planning degenerates into centralized-supply planning.

The barrier of the centralization bias can be tackled by insisting on least-cost planning which "is a process of examining all electricity-saving and electricity-producing options to select 
a mixture of options that minimizes total consumer cosi, often including consideration of environmental concerns and other responsibilities." ${ }^{18}$ To quote the least-cost planning order of the Wisconsin Public Utility Commission:

This order explicitly adopts a new approach to electricity utility planning which it calls 'Least-Cost Integrated Planning.' This term describes a process in which all reasonable options for both supply and demand are assessed against an array of cost and benefit considerations, which are defined as broadly as possible. The uniqueness of this approach is that it does not segregate supply-side options, such as generating plant or transmission lines, from the demand-side options, such as energy conservationi. Instead it seeks to evaluate all options on an integrated equivalent basis. The approach is also unique in the breadth and comprehensiveness of the costs and benefits to be used as measures. In addition to quantifiable economic costs and benefits, the options are evaluated against as many aspects of social and environmental values as possible. The breadth of scope of this analysis requires considerable creative thought and new ways of looking at utility systems.... ${ }^{\text {I9 }}$

The way of helping to surmount this barrier of the centralization bias is to increase the scope of supplies so that they include decentralized sources and then to insist on least-cost planning so that these decentralized sources find a place if their costs are lower.

C. The Supply-monopolists: Not only do the producers and distributors of energy carriers focus exclusively on the supply of carriers produced in a centralized manner, but quite often there are laws to prevent the production of energy carriers by any other producer. And, in the case of regulated electric utilities, purchases of power (from cogeneration, renewable sources and other non-utility sources) may add nothing to profits. The producers and distributors of energy carriers have become supply monopolists, and this has become a barrier to efficiency improvements with respect to the production of energy carriers.

Such a situation prevailed in the U.S. until the enactment and implementation of two important laws: PURPA, the acronym for Public Utility Regulatory Policies Act of 1978, which promotes cogeneration, and Regulations Governing Independent Power Producers of 1988, which promotes small power producers who use renewable energy sources. PURPA requires an clectric utility to purchase electricity from qualifying cogenerators and small power producers at the utility's avoided cost, i.e., at a price equal to the cost the utility avoids by not having to provide (by generation or purchase) that electricity. The laws have been extremely successful, because they have created a powerful cogeneration industry thanks to the windfall profits available to many cogenerators which can produce electricity at lower costs than utilities. Since the law gives all the financial benefits of cogeneration to the cogenerators, the cost savings should be shared (through lower rates) with rate payers after the cogeneration industry becomes well established. Hence, PURPA-like laws should only be temporary. 
Thus, the barrier of the supply-monopolist has to be overcome by measures that include the enactment of PURPA-type incentives which will encourage and reward independent producers to produce energy carriers.

\section{ACTUAL AND POTENTIAL COGENERATORS}

A. The Cogeneration-blind: There are several opportunities, particularly in the process industries, for the cogeneration of electricity along with steam. This cogeneration is a means of improving the efficiency of the generation of energy carriers. Despite this, the opportunities are rarely seized and exploited.

A telling example is that of the sugar industry in developing countries where bagasse (the ligneous residue left after the juice is extracted from the sugarcane) is burnt to produce the steam needs of the sugar factory and the in-plant requiremonts of electricity. By increasing both the pressure at which the steam is produced and also the efficiency with which the electricity is generated, it is possible to "export to the grid" the electricity that is in excess of the needs of the plant. ${ }^{20}$ In the case of Karnataka, for instance, it has been estimated ${ }^{21}$ that the potential exportable electricity is equal to the amount which could be produced by one of the $235 \mathrm{MW}$ nuclear reactors proposed for the state.

The reason why these opportunities are not seized is that actual and potential cogenerators do not have the legal sanction and financial rewards for exporting electricity to the grid.

Thus, the enactment of laws that will permit the export of cogenerated electricity to the grid at remunerative prices is an important measure that can contribute to overcoming the barrier of the cogeneration-blind actual/potential cogenerator.

\section{LOCAL/NATIONAL FINANCIAL INSTITUTIONS}

A. The Supply-biased: Just as the producers and distributors of energy carriers are obsessed with the supply aspect of the energy system, the financial institutions that provide the capital are also supply-biased.

The origin of this barrier is the conventional approach to energy followed by financial institutions. According to this approach, the purpose of the energy system is to increase energy consumption, which means that the emphasis has to be on increasing the supply of energy. Improving efficiency becomes a separate issue that is automatically ignored, because it does not lead to increases in supply and consumption.

This barrier has to be tackled first "in the realm of ideas," by propagating the paradigm that it is the level of energy services, rather than the magnitude of energy consumption, that is a true indicator of development. But a given energy service, say lumens of lighting, can be obtained either by increasing supplies or by using more efficient devices. For us to know which 
is the best way of obtaining that rervice, the various options must be compared with eack other. Hence, sound financial management requires that tenders must be called, not merely for augmenting supplies, but for providing the energy services that are necessary. In addition, energy-efficiency improvements must be included in the least-cost planning process.

Thus, the best way of helping to dismantle the barrier posed by the supply-biased institution is to shift the emphasis from energy consumption and supplies to energy services, to include efficiency improvements in the list of options for providing services and to pursue leastcost planning.

B. The Unfair: If there is concern for least-cost energy planning, then it must be ensured that the competition between supply increases (from centralized and decentralized sources) and energy-efficiency improvements is fair. In the first place, energy savings should be treated symmetrically with energy production. This might mean, for instance, that the expenses associated with energy-efficiency improvements are considered to be the cost of the service and used for a "cost plus"' method of charging customers as in the case of supply technologies. Then all three contenders - centralized sources, decentralized sources and energy-efficiency improvements -- must be compared on the same terms of credit (including interest rates), benefits, incentives, subsidies, etc. ${ }^{22}$ In other words, there must be what the Americans call a "level playing field" for the contenders.

At present, the competition is certainly not fair In particular, financial institutions tend to be quite unfair in their comparisons of supply increases and efficiency improvements; the advantages are heavily weighted in favour of centralized sources and against conservation measures with decentralized sources in between. The origin of this unfair discrimination can be traced to the fact that financial practices regarding energy have grown in association with the development of the centralized supplies and, over the course of time, a number of hidden subsidies and other supports for such supplies have evolved.

This barrier of unfair financial institutions must be responded to with a demand for fair competition through the elimination of subsidies to energy supplies, correct pricing (see Section VIII. H.), same terms of credits, benefits, incentives. etc.

C. The Anti-innovation Attitude: The technologies for energy-efficiency improvements are evolving rapidily. At any juncture, there are promising but not-yet-proven technologies. These new technologies have not yet passed through the innovation chain -- the sequence of steps (such as basic research, applied research, design, engineering for manufacturing, manufacturing and marketing) from idea or concept in the mind to product or process in the economy. Quite often, the important step of production, which is costlier than the other steps, needs to be completed. Unfortunately, technologies at this stage of development tend to fall between two stools; the agencies that fund R\&D do not support production as it is not considered research and development, and the financial institutions avoid supporting anything that is not-yet-proven. The anti-innovation attitude of the financial institutions is a barrier against the development of energy-efficiency technologies. 
Of course, there is a rationale behind this conservative attitude of financial institutions. Not all yet-to-be-proven technologies succeed in the marketplace. If, therefore, the banks want every new technology to be an assured financial success, no such assurance can be obtained. On the other hand, if the banks are looking for the success of a portfolio of technologies, rather than every single one, then this venture capital approach can lead to financial succeiss.

The allocation of a small percentage of the funds possessed by financial institutions towards venture-capital support of as-yet-unproven energy-efficient technologies can contribute to overcoming the barrier of the anti-innovation attitude of financial institutions.

\section{GOVERNMENT/COUNTRY}

a. The Uninterested Government: Most governments in developing countries believe that conservation is a rich country's game, because the term has been understood to mean making do with fewer energy services (for example, less light in homes). This recommendation for fewer services is obviously unacceptable, because the level of services is already low; Indian villages are "areas of darkness. ${ }^{23}$ As a result, decision makers in developing countries have shown a tendency to be uninterested in conservation measures. In fact, the enormous disparities in the level of energy services between industrialized and developing countries had led to a widespread popular pressure for stepping up the level of energy services. Thus far, this pressure has been understood by decision makers as an imperative need for escalating the magnitude of energy consumption (more kilowatt hours for lighting).

The real problem lies in the understanding of conservation. If conservation is understood not as making do with fewer energy services through reduced energy consumption, but as increasing energy services with less energy consumption (more light with fewer kilowatt hours) through energy-efficiency improvements, then energy efficiency can become the core of the development strategy.

In fact, if the preoccupation is only with the present needs of developing countries, then perhaps energy-efficiency improvements alone may be adequate. But, development requires industrialization, which in turn implies as a necessary condition the growth of the infrastructure and of the quantity of goods and services, measured by the gross domestic product (GDP). Annual growth rates of 5-10\% have become the standard goals, although only a few developing countries have achieved such growth targets.

The central question is: what growth rates in energy use are required to sustain these targets for GDP growth? When Western Europe and North America were industrializing, their energy consumption grew as fast as their GDP -- or faster -- in order to build the infrastructure of roads, bridges, houses and heavy industry. However, if a develrping country intends to implement the same process of industrialization today, the materials requirements and therefore energy demand can be dramatically less. This reduction is possible mainly as a result of two achievements of the materials revolution that took place during the past half century: first, the 
same materials can be produced with far less energy and, second, far smaller quantities of modern materials are required to satisfy the same need in a vehicle, bridge, building, etc. ${ }^{24}$

As a result, developing countries need not repeat the energy history of the industrialized countries; a much lower ratio of energy to GDP growth would be adequate for them to achieve comparable levels of industrialization. In fact, exploiting cost-effective opportunities for energy savings will speed up the rate of GDP growth. And, if the emphasis on energy efficiency is directed towards the new installations (where the energy savings are usually greater and cheaper than in the case of retrofits) and towards the energy-intensive basic industries (which will probably account for the lion's share of incremental consumption), developing countries can leapfrog technologically and outperform the most energy-efficient industrialized countries.

This does not mean that increases in energy supplies are unnecessary for developing countries. Significant inputs of energy are likely to be essential for the development process and, therefore, the extreme option of depending on conservation alone must be rejected.

What is required is a balanced approach in which there is a holistic integration or mix of three types of energy strategies: energy-efficiency improvements, centralized generation and generation from decentralized sources. The components of such a mix need not be identified in an ad hoc manner; a rational procedure can be used. One such procedure utilizes least-cost supply curves. Since it is invariably cheaper to save a kilowatt than to generate a kilowatt and to avoid transmission/transportation and distribution costs by generating at or very near the point of consumption, it turns out that many technologies for conservation and decentralized generation get included in the least-cost mix. This is particularly the case with energy efficiency in new plants and equipment and technological leapfrogging.

Technology mixes arrived at through this least-cost planning approach make possible major increases in the level of energy services with far less of an increase in the supplies of centralized energy than would have been required with conventional energy systems that are based exclusively on centralized sources. This is because the least-cost mixes include significant contributions from cost-effective conservation and decentralized sources. There is also an economic implication: the annual investment required for the energy sector goes down and becomes more manageable in a situation where capital is scarce. This implication arises from the fact that energy-efficiency improvements can increase GDP without a corresponding increase in energy consumption. Therefore, technology mixes that include conservation reduce the coupling between GDP and energy. ${ }^{25}$

A clear-cut national policy that includes a commitment to energy efficiency and least-cost planning would be highly desirable, but it is not an essential condition for the implementation of energy-efficiency improvements. The U.S., of course, is a well-known example of a country in which a great deal of progress has been achieved with regard to energy conservation even though it is not part of a national energy policy. The experience of PROCEL, the Brazilian energy-efficiency programme, also demonstrates that progress can be made towards more efficient electricity use even without broad support from policymakers, high electricity prices 
or a stable economy. What is critical is the commitment of at least a few prominent energy policymakers and experts, the institutional base of a utility base, a nationally based program serving short- and long-term needs and support for indigenous efforts and institutions. ${ }^{26}$

Thus, the economic advantages of making energy efficiency the core of the development strategy and of pursuing least-cost energy planning must be popularized and converted into public pressure to dismantle the barrier of the uninterested government. It is desirable that the government is made to adopt a clear national policy on energy-efficiency improvements translated into a coherent package of measures.

B. The Skills-short Government: The formulation and implementation of energy-efficiency programmes require technical and managerial skills of a higher order. It is precisely such skills that are usually in extremely short supply in developing countries where in fact the underdevelopment of human resources is the telltale evidence of underdevelopment. This inadequacy of trained technical and managerial personnel is a serious barrier to the implementation of energy-efficiency improvements.

The barrier of inadequate technical and managerial skills for the implementation of energy-efficiency improvements should be tackled by extensive and intensive training programmes.

C. The Government without Adequate Training Facilities: To train the skilled technical and managerial personnel necessary for the implementation of energy-efficiency improvements, training facilities and trainers are required. But most developing countries are characterized by the paucity of institutions for developing human resources and the shortage of trainers to train the requisite personnel.

The barrier of the lack of training facilities and the shortage of trainers has to be overcome by special programmes aimcd at developing the required training facilities and building up ? cadre of trainers.

D. The Government without Access to Hardware and Software: Even if a country has the trained technical and managerial personnel for implementing energy-efficiency improvements, the field is changing so rapidly that any training quickly becomes outdated. It is necessary, therefore, to have good access to information about technical developments in energy-efficiency hardware, as well as about policy and institutional achievements elsewhere regarding the use of such hardware. For instance, it is important not only to know about the latest developments with respect to compact fluorescent lamps, but also about the innovative financing and organizational schemes that are being tried out in other countries.

Actually, what is required is access to and absorption of technology. This process requires much more than the mere transfer of infermation; it involves climbing the "know -how ladder" from operational know-how to maintenance know-how to construction know-how to design know-how. 
The barrier of inadequate access to information about the hardware and software of energy-efficiency improvements has to be tackled by providing this access through continuously updated menus of technologies for a particular energy service as well as menus of policies to implement an improvement in a particular service. In addition, the acquisition of know-how and the absorption of technology are crucial.

E. The Capital-short Government of an Infrastructure-poor Country: To reap the full potential of energy-efficiency improvements, it is vital to have a sound infrastructure for transportation, stabie energy supplies, etc. In many developing countries, this infrastructure is woefully inadequate; the roads are poor, the rail network minimal, the supplies of energy highly unreliable, etc. Investments on building up this infrastructure appear to be the first priority.

But governments, like poor and/or first-cost-sensitive consumers, can have very high discount rates and display great reluctance to invest capital in energy-efficient infrastructures and technologies. It may well be the case that the improvement of roads may be the best way of improving the fuel efficiency of vehicles or that expansion of the rail network may be the most effective means of reducing oil consumption for freight and passenger transport, but both these measures require massive investments today to reap benefits in the future. Similarly, the maintenance of existing infrastructure may be far more cost-effective than the creation of new infrastructure, but maintenance may require considerable investments in the training of technical personnel. So, when there are innumerable other urgent demands upon the governments of countries where the basic minimum needs of the population have not been satisfied, the scarcity of capital is a barrier to investments in the vital infrastructures that are the basis of energyefficiency improvements.

The barrier caused by capital scarcity for a government that must build the infrastructure necessary to exploit energy-efficiency improvements has to be tackled by international aid and funding agencies in the same way as in the case of poor and/or first-cost-sensitive consumers - the first costs must be converted through loans or aid into operating costs.

F. The Sales-promoting Regulator: In most countries, the prices of energy carriers (electricity, coal, petroleum products) are regulated by the government or by autonomous bodies set up by the government. Unfortunately, the rate-setting formulas are often so biased towards the supply of energy carriers that they discourage investments in improvements in the efficiency of the utilization of these carriers. This situation is the result of profits being coupled to sales so that if the producer of an energy carrier makes investments in demand-side programmes, it not only loses revenues due to decreased sales, but also loses returns on its investments in demand reduction. This sales bias held by the regulators of energy carriers has become a barrier to the marketing of energy-efficiency improvements.

In such a situation, the regulators can play a central role. Instead of simply pressuring the distributor of the energy carrier to establish energy-efficiency programmes, regulators should modify the reward structure and give the energy company a financial stake in exploiting opportunities for cost-effective improvements in energy efficiency. ${ }^{27}$ 
Financial incentives are needed, therefore, to make conservation programs successful. But in designing these incentives, economic efficiency and equity must be ensured by developing effective mechanisms for marketing energy services.

An interesting approach is that followed by the Oregon Public Utility Commission, which sought to increase market penetration of new energy-efficiency technologies by giving its utility, Pacific Power and Light Co. (PPL), a profit incentive to promote conservation. ${ }^{28}$ PP\&L provides energy conservation services to customers. The customer will pay an amoun ${ }^{29}$ over time (15 years) that fully compensates PP\&L for its costs with respect to program expenses and lost revenues due to conservation. PP\&L can add conservation investments to its rate base to increase earnings. However, the increase of rates due to the increased rate base is equal to the decrease in rates due to revenues from energy service charges; hence, there is no increase in rates for non-participants. ${ }^{30}$

In effect, the utility is supplying "saved electricity" and selling energy services to conserving customers, and the customer is buying saved electricity like buying generated electricity. Thus, the new regulations decouple profits from sales and allow utilities to recover costs (and make a profit) fron successful demand-side programmes. The regulations maximize conservation efforts by utilities by providing adequate incentives and allowing for recovery of conservation expenditures.

An alternative approach involves energy service companies (bidding in auctions) to sell saved electricity to utilities which buy the saved electricity just like they buy non-utilitygenerated electricity (thanks to PURPA) and then sell the services to conserving consumers.

A more fundamental and wide-ranging approach is for the regulators to set utility conservation programs within a formal least-cost planning framewo- $k$ and to make the least-cost plan consistent with the utility's profit-maximizing strategy. The objective of least-cost planning is best achieved in an institutional framework where planners understand in detail the complexities of both supply and demand issues relating to the energy carriers. In other words, utilities are best suited for carrying out and implementing least-cost planning.

Unfortunately, the rational response of the utility industry to the economic environment in most countries is strongly skewed against least-cost planning. The incentive structure arising from the current system of regulation is a serious barrier to successful least-cost planning.

Regulatory reforms that decouple profits from sales and allow utilities to recover costs (and make a profit) from successful demand-side programmes are necessary to overcome the barrier of the sales bias of the regulators of energy carriers. Regulatory reforms are also required to "remove the disincentives to least-cost planning and to make the successful implementation of a utility's least-cost plan its most profitable course of action. ${ }^{31}$

G. The Powerless Energy-efficiency Agency: Even if governments are interested in energy efficiency, they terid to create a separate cell (centre, department or ministry) for it. 
Unfortunately, such a separate entity cannot wield enough power to enforce energy-efficiency decisions on other departments and ministries. By and large, the energy-efficiency agency of the government ends up confining itself to publicity and information. The barrier in this case is that of the powerless energy-efficiency agency.

Since energy enters every economic activity, it therefore cuts across all economic ministries. If energy efficiency is to become the core of the development strategy, the agency responsible for efficiency improvements must have sufficient clout. This will happen only if the agency responsible for improving efficiency is (1) outside and above the energy system and energy ministiy and (2) under the highest, or very high, political and/or financial authority. One of the suggestions in this context is that the energy-efficiency agency must be under the highest political and/or financial authority -- the Prime Minister or the Finance Minister in a parliamentary system or the Office of the President in a presidential system. The necessary condition then would have been satisfied for the agency to be powerful enough to see that the decisions regarding efficiency improvements are implemented by all departments and ministries.

The key to Japan's energy-efficiency gains is that the clear national policy (translated into a coherent package of measures) is firrnly administered by a single agency with the authority and influence to ensure that measures are implemented across all sectors. In Japan, the October 1979 "Law Concerning the Rational Use of Energy" was formulated and implemented by the Ministry of International Trade and Industry (MITI), an elite ministry on par with the Ministry of Finance and the Foreign Dffice, with a wide sphere of influence across most sectors and Ministries. In contrast, the U.K. has relatively less success in improving energy efficiency, and this can be ascribed to the fact that its Energy Efficiency Oifice does not have the authority to implement inter-ministerial initiatives. And, India has started its Energy Management Centre as an autonomous society under the Department of Power!

Thus, major step towards surmounting the barrier of the powerless energy-efficiency agency consists of locating the agency outside and above the energy system and under a sufficiently high political authority to ensure that the required measures are implemented across all sectors and ministries/departments/agencies.

H. The Cost-blind Price-fixer: Energy prices in developing cuuntries are generally no reflection at all of the real costs of generating energy and the true costs to society; they include large elements of subsidy. In such situations, the frugal are not rewarded and the profligate are not punished. Consumers do not feel the pinch of energy prices and do not receive the proper signals regarding the value of energy resources. Also, the energy consumption of these consumers tends to be largely unaffected by small increases in the price of energy. Since energy prices in these countries are administered prices fixed by the government, the cost-blindness of these governments has become a barrier to the dissemination of efficiency improvements. ${ }^{32}$

Prices should be determined, not by the average costs of cheap supplies established in the past, but by what it will cost to generate energy in the future. What matters is not the sunken cost of the previous unit of energy, but how much it will cost to generate the next unit 
for the next consumer in the future. That is, prices should reflect the long-run cost of producing the next unit of energy in new generating stations -- what the economists call long-run marginal cost pricing - because that is what the energy companies will have to pay to set up facilities to deliver this next unit.

Attempts have to be made to move in the direction of long-run marginal cost pricing, but the political barriers in the way of increasing prices must not be underestimated. ${ }^{33}$ An important policy guideline in this context is that consumers are more concerned about their energy bills than about energy prices. This means that efficiency improvements must be implemented simultaneously with price increases so that the decrease in expenditure brought about by the efficiency improvement compensates (fully or partially) for the increase in expenditure due to the price increase. ${ }^{34}$

Thus, the barrier of the cost-blind price-fixing government can be addressed by a move towards long-run marginal cost pricing and by ensuritig that efficiency improvements are implemented along with price increases.

I. The Fragmented Decision Maker: Since the conventional approach emphasizes energy consumption, its attention turns to supply increases, which are then differentiated into those from centralized and those from decentralized sources. Conservation becomes a separate issue. As a result, centralized and decentralized supply increases and energy-efficiency measures become separate decisions handled in separate offices by separate departments or ministries with separate budgets. In such a contest, empires and satrapies develop. And, in the ensuring conflict over funds, centralized supplies (with the strongest lobbies) get the biggest budgets, decentralized sources get much less, and energy efficiency has to be content with the leftovers.

But any energy service, such as lighting, can be obtained either by increasing centralized or decentralized supplies or by using more efficient devices and equipment. To identify the most cost-effective way of obtaining that service, each of them must be compared with the others. Hence, sound management requires that tenders must be called, not for augmenting supplies, but for providing the energy service at the least financial cost.

Hence, the barrier of fragmented decision making can be tackled by ensuring that efficiency improvements are incorporated into the same investment decision as that considering energy supply, are made in the same office by the same decision maker and are included in the least-cost planning process.

J. The Large-is-impressive Syndrome: Government decision makers are very much concerned with the political "pay-off" and "mileage" they can get out of their decisions. They tend, therefore, to estimate the comparative "political returns" from technological choices. And, in making this estimate, they invariably view large plants as impressive and grand exhibits that stand as permanent testimonies to the decision maker's concern for the populace. In contrast, each decentralized unit is relatively unimpressive and short-lived, and the set of such technologies is invisibly diffused over the countryside. 
There are also the management aspects. Large projects are easier to manage, monitor and police with centrally controlled personnel. In contrast, small dispersed technologies require decentralized modes of management, monitoring and policing, perhaps best based on the initiative and participation of local organizations. All this decentralization can be an anathema to undemocratic governments and a nightmare to entrenched bureaucracies. The story goes that a cynical bureaucrat said: "If you spend \$7 million on a programme of constructing improved fuel-efficient stoves (which have components that are pilferable and breakable), you can end up with neither the $\$ 7$ million nor the stoves, but if you spend $\$ 350$ million on a large project, you are left with a dam or a power station even if $20 \%$ is siphoned off by way of commissions!"

In the ultimate analysis, however, it is only genuine people-oriented developmental activities that will earn lasting political support. Large projects will impress only if they really advance the satisfaction of needs, strengthen self-reliance and upgrade the environment.

Thus, the barrier of the government decision maker with the large-is-impressive syndrome can be tackled only by stressing the developmental aspects of energy projects and by exerting consumer demand in fayour of those projects (large or small) that advance genuine development.

K. The Large-is-lucrative Approach: The unfortunate but inescapable reality in many countries and regimes is that expenditures on projects include commissions (legal or illegal) to the decision makers. In such situations, it is obvious that the magnitude of the commission is proportional to the expenditure on the project, so that there is an inherent tendency to favour large projects, pursue "maximum-cost" planning and ignore cost-effective options. In this economic environment of commissions, the large-is-lucrative approach is a major barrier to cost-effective energy-efficiency improvements.

Forcing decision makers to adopt least-cost planning is an important way of securing atterition for cost-effective energy-efficiency improvements and undermining the large-is-lucrative barrier.

\section{INTERNATIONAL, MULTILATERAL AND INDUSTRIALIZED COUNTRY FUNDING/AID AGENCIES}

A. The Exporters of Inefficient Technology: Since the oil-price shocks of the 1970s, there has been considerable progress in energy efficiency in the industrialized countries. In this process, a number of the energy-inefficient technologies of the earlier era have been replaced with modern energy-efficient technologies. But, in the developing countries, the process of efficiency improvement has not taken place to the same extent. This is primarily a result of the transfer of energy-inefficient technologies to the developing countries, which have always depended heavily on technology imports from the industrialized countries.

A basic difference between industrialized and developing countries must be emphasized here. Whereas industrialized countries had large stocks of inefficient equipment to be replaced, 
developing countries are very much more of a "blank sheet." Much of what the developing countries have may be inefficient, but fortunately, they do not have too much of it. Hence, they can leapfrog technologically by adopting energy-efficient technologies without going through the intermediate phase of large-scale energy inefficiency.

This barrier to energy efficiency created by the exporters of energy-efficient technology can be tackled by assistance with technology assessment, by favouring energy-efficient technologies in aid programmes and by supporting technological leapfrogging in developing countries.

B. The Supply-biased: Just as the producers and distributors of energy carriers and financial institutions are obsessed with the supply aspect of the energy system, the international, multilateral and industrialized country agencies that provide the funds and aid are also supplybiased.

The origin of this barrier is the conventional approach to energy followed by these international, multilateral and industrialized country agencies. According to this approach, the purpose of the energy system is to expand energy consumption, which means placing an emphasis on increasing the supply of energy. Hence, improving efficiency becomes a separate issue that is automatically ignored, because it does not lead to increases in supply and consumption.

This barrier has to be tackled at the conceptual stage by propagating a paradigm shift. Instead of judging development by the magnitude of energy consumption, it must be measured by the level of energy services. But there are several options for improving energy services -in particular, they can be increased either by expanding supplies or by using more efficient devices. For these agencies to know which is the best way of obtaining that service, various options must be compared with each other. Hence, sound financial management requires that tenders must be called, not merely for augmenting supplies, but for providing the energy services that are necessary. In addition, efficiency improvements must be included in the leastcost planning process.

Thus, the best way of contributing to the dismantling of the barrier posed by the supplybiased is to shift the emphasis from energy consumption and supplies to energy services, to irclude efficiency improvements in the list of options for providing services and to pursue leastcost planning.

C. The Anti-innovation Attitude: Another barrier is the reluctance of international financial institutions, such as the World Bank, to fund new-but-yet unproven technologies. The reasons for this attitude at the international level are virtually the same as those (see Section VII. C.) influencing local and national financial institutions. However, the implications are even more serious. 
The anti-innovation attitude results in even the most promising of these technologies being. unable to find financial support for completion of the innovation chain. This is particularly the case with technologies for energy-efficiency improvement and for renewables -- especially technologies for biomass production and biomass-based energy. Also, the development of some techmologies may require collaboration between institutions in industrialized countries and developing countries. If international support cannot be found for such collaboration, it can proceed only with bilateral funding, which often precludes funding of R\&D in the industrialized country.

The barrier of the anti-innovation attitude of international financial institutions can be addressed by reserving a small percentage of the funds of these institutions for venture-capital support and assistance of promising but as-of-yet-unproven energy-efficiency technologies.

D. The Large-is-convenient Funder: The international, multilateral and industrialized country agencies that provide the funds and aid for energy projects are large bureaucracies doing a great deal of paperwork. And the paperwork and administrative expenditures (site visits, for example) necessary to fund a project are roughly the same for a large project of $\$ 1$ million as for a project of $\$ 10,000$. So, if there is a $\$ 1$ million budget and a choice has to be made between one large project of $\$ 1$ million and 100 projects of $\$ 10,000$ each, the bureaucracy tends to choose the large project to avoid 100 times more paperwork. ${ }^{35}$

The way of helping to overcome the barrier of a funding bureaucracy that finds it convenient to support large projects is to arrange for funding a programme administered by an agency that can execute the large number of small projects.

E. The Project-mode Sponsors: Financial support for energy activities from aid agencies has invariably been project-oriented, typically biased to large supply projects (e.g., the construction of massive hydroelectric dams). This tendency is partly due to the large-is-convenient syndrome described in the previous section. Aid in the project mode may be appropriate for supplyoriented energy strategies, where the preoccupation is with massive energy plants. But this approach is a barrier to implementing energy-efficiency programmes that emphasize a larger number of diverse and often small-scale technologies to suit regional and local conditions. The implementation of a large number of small projects is impractical with project-type support in which the disbursal of funds is closely administered by the funding agency.

The barrier arising from project-mode sponsors has to be overcome by measures that include the reorientation of aid from specific projects to broad programmes. for which the detailed allocation of programme resources is largely the responsibility of locally based institutions and in accordance with the overall programme objectives.

F. The Self-reliance Underminers (alias the Dependence-perpetuators): A drawback of the policy of shifting from project to programme support is that most developing countries may not have the technological and management institutions and expertise to plan and administer such programmes. In fact, this is another reason why aid support has not emphasized programmes 
but instead has supported projects that are closely and namowly defined at the proposal stage, thus allowing aid agencies not to have to rely much on local institutions and capabilities.

The solution to this problem is to devote efforts to building institutions and strengthening indigenous capability. Even though the long-term payoffs of such efforts are sure and enormous, aid agencies see this as a time-consuming and frustrating task. They cannot resist the temptation of achieving what they perceive as "quickie successes." In the process, they debilitate indigenous technological capability, undermine self-reliance and perpetuate dependence.

First, a portion of the aid should be directed to building the necessary energy-related institutions and enabling them to support staff who are familiar with local development problems and who are capable of carrying out the needed technology assessments, formulating the appropriate programmes, monitoring these efforts and improving programmes in the light of field experience.

The large utility companies of developing countries are particularly attractive candidates for "institutional renovation." These companies can bring about this change by reorienting their technically competent staff from being preoccupied with the expansion of energy supplies to administering broad energy service programmes. As this institutional capability is developed, a greater and greater shift from projects to programmes could take place.

Traditionally, aid has not been very effective in directly fostering local technical capability. In part, this weakness has resulted from the emphasis on large projects for which highly specialized support services are required. The result has been that procurement and consulting arrangements are frequently left to foreign companies, which become better and better at providing these skills. Another and perhaps more important reason is that most of the large loans and grants managed by international and multilateral organizations are given specifically to cover expenses involving foreign currency. Local expenditures are not covered by the loans. A typical loan covers about one-third of the overall project cost. The aid money, therefore, is spent mainly on consultancy and engineering services and on machinery imported from abroad. Often, a sizeable fraction of bilateral support must be spent in the donor's country and/or on its personnel.

These practices, which are de facto methods of recycling the aid back to the donor country, are not consistent with facilitating and strengthening self-reliant energy-efficiency efforts. They tend to be more of a zero-sum game (what the foreign consulting firm gains, the indigenous group loses) than a win-win situation (in which the foreign and local groups benefit synergistically). Much more in the interests of the aided country is a policy that strengthens the indigenous technical capability and stipulates that:

(1) before foreign consultancy services are recruited, they are deemed both essential and unavoidable, and when foreign consultants are hired, measures be taken to associate local groups with the project/programmes; and 
(2) a significant fraction of the aid be spent in the recipient countries, thereby contributing to building the local technical capability.

Thws, the sure way of overcoming the barrier created by the self-reliance underminer and the dependence-perpetuator is to devote considerable and meticulous effort to the initiation/ establishment/strengthening of indigenous capability in the areas of energy analysis and planning and energy technologies.

\section{CONCLUSIONS}

A. Combinations of Measures for Qvercoming Barriers: As already stressed, a one-barrier-onemeasure approach must be avoided. In the first place, even a single barrier may consist of a number of sub-barriers. For example, attempts to formulate and implement energy-efficiency standards (EES) may be hindered by the following sub-barriers: unfamiliarity with EES as a policy tool, lack of capability to design EES, incomprehensible EES, inability to design credible tests, inability to enforce EES, markets too small to attract manufacturers and incompatibility between EES and consumer interests. ${ }^{36}$

Further, since two or more barriers can operate simultaneously and since, even if there is a single barrier, the corresponding measure may not be a sufficient condition for overcoming it, single-measure efforts are not likely to bear much fruit. Combinations or packages of measures increase the effectiveness of the implementation of energy-efficiency improvements.

The situation is analogous to that shown by innovations, where according to "Berg's theorem, ${ }^{n 77}$ those innovations spread which simultaneously meet several consumer demands. The point is that the introduction of a new technology is a major perturbation to society. It creates new uncertainties regarding costs and benefits and threatens many vested interests seeking to perpetuate the status quo. No wonder those technologies that are successful are those that potential purchasers cannot afford to reject, because they are superior on several count; compared to existing technologies.

Similarly, in the case of energy-efficiency improvements, those packages of measures are likely to succeed that overcome several barriers simultaneously. A package that is implemented quite often consists of a combination of fiscal incentives, price controls, technical R\&D, publicity and educational measures and legislation encompassing the public and private sectors, individuals and organizations.

From this point of view, energy service companies are in fact combination packages, because they are "single-window" agencies for implementing all components of energy-efficiency programmes -- providing information, assessing requirements, financing, organizing contractors, etc. Thus, the concept of the energy service company is not just one of many approaches that can be taken. It is far more than a mere consumer information program or a conservation loan program. It satisfies the four criteria that must be satisfied by a successful large-scale program that seeks to capture the full economic potential for conservation: 
(1) it deals with the high consumer discount rate;

(2) it is profitable for the companies involved;

(3) it can avoid penalizing non-participants; ${ }^{38}$ and

(4) it can ensure that estimated savirgs are close to actual savings. ${ }^{39}$

B. Combinations of Measures at the Strategic Level: Quite often it is not sufficient to implement measures in an isolated way at the policy level. It may be essential to implement a comprehensive strategy.

Least-cost planning can be viewed as such a comprehensive strategy for ensuring a rightful place for energy-efficiency improvements while guaranteeing consideration for decentralized sources and centralized supplies. It also necessitates a treatment of both the demand and supply aspects and a comparison of costs on the same terms. Least-cost planning may turn out to be one of the most powerful ways for improving energy efficiency.

Similarly, the following comprehensive strategy may be required for the improvement of the efficiency of vehicles fueled with petroleum products: ${ }^{40}$

o technological improvements in the fuel efficiency of vehicles (through better power plants, transmissions, vehicle design, lubricants, tires and materials);

o reductions in the total vehicle miles travelled (VMT) through traffic control, behavioural changes, increased public transport, land-use changes and parking regulations; and

o promotion of alternative fuels (methanol, ethanol, electricity, hydrogen).

A four-pronged strategy has been proposed to reduce India's dependence upon petroleum products.

o efficiency improvements in the use of petroleum products;

o shift of passer'gers from personal to public transportation;

0 shift of freight from truck to rail; and

o shift to non-oil fuels.

C. Policy-assisted, Market-oriented Mechanisms: Another important conclusion concerns the power and limits of the market. Whatever the virtues of the market as an allocator of capital, raw materials and manpower, it cannot be depended upon to safeguard equity, externalities (in particular the environment) and long-term interests. Special policies have to be devised to protect the poor, the environment and future generations.

In particular, many of the barriers result in an imperfect market for efficiency improvements. For instance, the market displays a negative feedback $;{ }^{41}$ the more effective the energy-efficiency measures, the less the requirement of energy, the lower the price of energy and, therefore, the less the demand for energy efficiency. This means that price mechanisms alone will not work and market forces by themselves will not achieve the potential for energy efficiency. ${ }^{42}$ Since the spread of energy-efficiency improvements cannot be left to the market, 
there has to be an emphasis on policy-assisted, market-oriented mechanisms for promoting energy efficiency. Hence, marginal-cost pricing and regulations are important means for making conservation investments profitable to utilities.

It is useful to distinguish -- as Yokobori has done ${ }^{43}$-- between three types of potential for energy-efficiency improvements: the market, economic and technical potential. The market potential is much less than the economic potential because of market distortions and high discount rates, and the economic potential in turn is not as great as the technical potential, because many technologies have not yet been made cost-effective and economically viable. Hence, the first major cilallenge is to assist the market in delivering economically viable conservation technologies, and the second challenge for public policies is to promote the flow of new energy-efficient technologies to the marketplace.

D. Innovation - A Grander Vision: Finally, it is necessary to have a grander vision than energy-efficiency improvements. Promoting innovation rather than energy efficiency per se is likely to be an especially effective way of improving efficiency (as long as energy is priced correctly). Here, too, Berg's important point about innovation is relevant; minimizing total production costs (and thus encouraging new technology) will often lead to lower energy use than minimizing life-cycle energy costs (which could prolong the life of obsolete technology). This stress on innovation necessarily means an emphasis on research and development, which in the ultimate analysis is the hope for the future. ${ }^{44}$

\section{ACKNOWLEDGEMENTS}

The author would like to thank Jayant Sathaye for inviting him to present this paper at the workshop at the Lawrence Berkeley Laboratory. Thanks should also go the author's colleagues, Jayaram Sankaran and G.B. Raghavendra, for arranging a seminar at the Department of Management Studies, Indian Institute of Science. Several members of the Berkeley and Bangalore audiences made useful comments and suggestions which have influenced the revision of the draft. To Vimala Reddy must go the author's thanks for helping to streamline the table of barriers, origins and measures. The author is particularly grateful to Dilip Ahuja who went through the draft with a fine comb and made a number of perceptive comments. Finally, the author must extend very special thanks to Robert Williams who, with his characteristic rigour and thoroughness, revealed the shortcomings of the first draft and, with his insight and perspective, showed how to fine-tune the paper and increase its scope and validity.

Dr. Reddy is the former chairman of the Department of Management Studies, Indian Institute of Science, Bangalore, India. Communications to the author should be sent to: Amulya K.N. Reddy, 7/12 Palace Cross Road, Bangalore, INDIA 560020. 
Table 1. Barriers to energy-efficiency improvements, their origins and measures to help to overcome them

\begin{tabular}{lll}
\hline \# Barrier & Origin of Barrier & $\begin{array}{l}\text { Measure(s) Suggested for } \\
\text { Helping to Overcome } \\
\text { Barrier }\end{array}$ \\
\hline
\end{tabular}

\section{ENERGY CONSUMERS}

$\begin{array}{ll}\text { 1.1. The Ignorant } \quad \text { Ignorance/Lack of training } & \begin{array}{l}\text { Information via } \\ \text { Publicity/Demonstration, } \\ \text { Training }\end{array}\end{array}$

1.2. The Poor and/or Firstcost-sensitive

Poverty and/or First-cost sensitivity

\subsection{The Indifferent}

1.4. The Helpless

1.5. The Uncertain

1.6. The Inheritors of Energy Inefficiency
Energy costs are small part of total costs

Lack of know-how re: identification, procurement, installation, operation \& maintenance of efficient devices/equipment

Uncertainty of future energy prices make it difficult to estimate cost/benefits of efficiency improvements

Those who pay the energy bills on end-use devices and equipment are not the ones who make the capital investments
Conversion of capital costs into operating costs through innovative financing/leasing/rebate schemes

Government intervention through regulations, standards, equipment labelling, rationing, etc.

Nurture efficiency improvement industry supplying total hardware + software packages

Stabilization/slow change of prices. External financing of investments \& recovery at guaranteed rate Equipment labelling (to generate market demand for energy efficiency) buttressed by regulations and standards

Regulation, standards \& equipment labelling; Equipment financing tied to energy efficiency 

\# Barrier
Origin of Barrier

Measure(s) Suggested for Helping to Overcome Barrier

\section{PROVIDERS OF END-USE EQUIPMENT}

3.1. The Operating-cost-blind Those who make the capital investments do not have to pay the operating costs
Equipment labelling to generate market demand for energy efficiency buttressed by regulations and standards

\section{PRODUCERS \& DISTRIBUTORS OF ENERGY CARRIERS}

4.1. The Supply-obsessed

4.2. The Centralizationbiased

4.3. The Supply-monopolist
Preoccupation with supply \& lack of interest in end-use efficiency because profits are coupled with sales

Preoccupation with centralized supplies

Legal monopoly exercised over carrier production

\section{ACTUAL/POTENTIAL COGENERATORS}

$\begin{array}{ll}\text { 5.1. The Cogeneration-blind } & \text { Ignorance of cogeneration } \\ & \text { potential; Legal restrictions } \\ & \text { on export of cogenerated } \\ \text { electricity }\end{array}$

Change of charter from suppliers of carriers to vendors of energy services. Growth in independent energy service companies

Increasing scope of supplies to include decentralized supplies; Least-cost planning

Breaking monopoly over supply by legislation (e.g., PURPA) to encourage independent production of carriers and sale to utilities

Dissemination of information on cogeneration potential; Enactment of PURPA-type laws that will permit the export to the grid of cogenerated electricity at remunerative prices 


\begin{tabular}{lll}
\hline \# Barrier & Origin of Barrier & $\begin{array}{l}\text { Measure(s) Suggested for } \\
\text { Helping to Overcome } \\
\text { Barrier }\end{array}$ \\
\hline
\end{tabular}

\section{LOCAL/NATIONAL FINANCIAL INSTITUTIONS}

\subsection{The Supply-biased}

6.2. The Unfair

6.3. The Anti-innovation Attitude
Focus on energy consumption and supplies, not on energy services

Supplies and efficiency improvements not compared on equal terms

Risk in funding new but yet unproven technologies
Belief that conservation is not for developing countries because their consumption levels are already too low

Technical and managerial skills to formulate and implement efficiency programmes in short supply

7.3. The Government w/o adequate training facilities
Lack of training facilities and shortage of trainers
Shifting focus from energy consumption to energy services; Inclusion of efficiency improvements in options for providing service; Least-cost planning

Fair competition between supply increases and efficiency improvements by eliminating subsidies to energy supplies, correct pricing, same terms of credits, benefits, incentives, etc.

Venture capital funds from financial institutions for support of promising but yet unproven energyefficiency technologies

Generating public pressure to make efficiency improvements the core of development strategy, the basis of national policy and an integral part of leastcost planning

Extensive and intensive training programmes

Develop the required training facilities and build up a cadre of trainers 


\begin{tabular}{lll}
\hline \# Barrier & Origin of Barrier & $\begin{array}{l}\text { Measure(s) Suggested for } \\
\text { Helping to Overcome } \\
\text { Barrier }\end{array}$ \\
\hline
\end{tabular}

7.4. The Government w/o Access to Hardware and Software

\subsection{The Capital-short \\ Government of an \\ Infrastructure-poor Country}

7.6. The Sales-promoting Regulator

7.7. The Powerless Energyefficiency Agency

7.8. The Cost-blind Pricefixer
Training becomes outdated. Inadequate access to info on hardware \& software developments

Capital-short governments have very high discount rates (are first-cost sensitive) and are reluctant to invest in efficient infrastructures and technologies

Profits are coupled so that demand-side investments lose revenues due to increased sales and lose retums on demand-side investments

The energy-efficiency agency does not have enough clout because it is merely a part of the energy ministry

Government-administered prices do not reflect the real costs
Access to hardware \& software through continuously updated technology and policy menus. Acquisition of know-how and absorption of technology

First costs must be converted into operating costs through loans or aid

Regulatory reforms (1) to decouple profits from sales $\&$ allow utilities to make a profit from successful demand-side programs and (2) to make least-cost planning a utility's more profitable course of action

Locating energy efficiency under a sufficiently high political authority to ensure that measures are implemented across all sectors and ministries

Long-run marginal cost pricing; efficiency improvements must be implemented along with price increases to offset the latter 


\begin{tabular}{lll}
\hline \# Barrier & Origin of Barrier & $\begin{array}{l}\text { Measure(s) Suggested for } \\
\text { Helping to Overcome } \\
\text { Barrier }\end{array}$ \\
\hline
\end{tabular}

\subsection{The Fragmented} Decision Maker

\subsection{The Large-is-} impressive Syndrome

7.11. The Large-is-lucrative Approach
Decisions re: efficiency improvements are made separately from decisions re: supply increases

Large centralized plants have bigger political "payoff" because they are impressive

In economic environment of legal/illegal commissions, large projects are favoured cost-effective options are ignored \& "maximum-cost" planning is pursued
Decisions re: efficiency improvements made part of the same investment decision as that considering supply and made in the same office by the same decision maker; Efficiency improvements included in least-cost planning

Stress developmental aspects of energy projects $\&$ generate consumer demand in favour of those projects (large or small) that advance genuine development

Adopt least-cost planning to secure attention for costeffective energy-efficiency improvements

\section{INTERNATIONAL, MULTILATERAL \& INDUSTRIALIZED COUNTRY FUNDING/AID AGENCIES}

\subsection{The Exporters of Inefficient Technology}

\subsection{The Supply-biased}

\author{
Export of obsolete energy- \\ inefficient technologies
}

Focus on energy consumption and supplies, not on energy services
Technology assessment assistance; Exporting energy-efficient technologies; Supporting technological leap-frogging by developing countries

Shifting focus from energy consumption to energy services; Inclusion of efficiency improvements in options for providing service; Least-cost planning 


\begin{tabular}{lll}
\hline Barrier & Origin of Barrier & $\begin{array}{l}\text { Measure(s) Suggested for } \\
\text { Helping to Overcome } \\
\text { Barrier }\end{array}$ \\
\hline
\end{tabular}

8.3. The Anti-innovation Attitude

8.4. The Large-is-convenient

8.5. The Project-mode Sponsors

8.6. The Self-reliance Underminers (alias the Dependence-perpetuators)
Risk in funding new and yet unproven technologies

Less paperwork to support few large projects than many small projects

The appropriateness of the project mode for large, centralized energy plants has g" "ed the approach to small projects as well

More convenient to use known "beltway bandits" and western in stitutions and experts
Venture capital funds from financial institutions for support of promising but yet unproven energyefficiency technologies

Programme support to agency that administers large number of small projects

Shifting emphasis from project to program support

Using indigenous expertise; Strengthening indigenous technological institution and capability 


\section{ENDNOTES}

1. Though the understanding upon which this paper is based has been derived from experiences in the Indian context, it has also benefitted from discussions with energy analysts in the industrialized countries and from a study of literature pertaining to those countries. As a result, it is likely that a great deal of the discussion here is just as applicable to the industrialized countries, and there is no need to append to the title the usual caveat: "with special reference to the developing countries." Incidentally, in omitting this caveat, the paper follows the practice of most authors from industrialized countries writing in the international journals who do not specify that their papers are relevant primarily to those countries even when that is clearly the case.

2. Apart from the papers referred to through endnotes at appropriate points of the text, the following papers were found to be particularly illuminating.

Geller, H.S. Electricity Conservation in Brazil: Status Report and Analysis. Washington, D.C.: American Council for Energy-Efficient Economy, November 1990.

Geller, H.S. et al. Getting America Back on the Energy-Efficient Track: No-Regrets Policies for Slowing Climate Change. Washington, D.C.: American Council for Energy-Efficient Economy, 1990.

Hillsman, E.L. and F. Southworth. "Factors That May Influence Responses of the U.S. Transportation Sector to Policies for Reducing Greenhouse Gas Emissions." Transportation Research Record. Washington D.C.: Transportation Research Board, National Research Council, 1990

Hirst, E. and M. Brown. Closing the Energy Efficiency Gap: Barriers to Improving Energy Efficiency. Oak Ridge, TN: Oak Ridge National Laboratory, January 1990.

Kempton, W. and M. Neiman, eds. Energy Efficiency: Perspectives on Individual Behaviour. Washington, D.C.: American Council for Energy-Efficient Economy, 1987.

Levine, M.D. et al., Energy Efficiency, Developing Nations and Eastern Europe: An Analysis of Key Issues. A report to the U.S. Working Group on Global Energy Efficiency. Washington, D.C.: International Institute for Energy-Efficient Economy, June 1991.

Meyers, S. et al., Energy Efficiency and Household Electrical Appliances in Developing and Newly Industrialized Cousitries. LBL-29678 UC-350. Berkeley, CA: Applied Science Division. Lawrence Berkeley Laboratory, December 1990.

3. To quote Robert H. Williams (personal communication, December 15, 1990): "As far as quality is concerned, available information is often not accurate, even in cases where a good, easily understood, readily measurable performance index is available -- e.g., auto fuel economy: in the U.S. the rating on a new car usually overestimates the performance, although it usually 
orders the performance of different cars correctly. And in the case of many conservation measures for buildings, estimated savings are often less than the actual savings. There is also the potential for fraud. And, the consumer may not believe energy savings information even if it is true. Except for rate instances such as the automobile, the consumer usually has no way of independently verifying energy savings claims.... Many people are unable or at least unwilling to learn what they need to know. The hassle of organizing an energy conservation effort can be great relative to other things people have to do, either in business or in their private lives."

4. L. Taylor (with I. Brown and S. Boyle), Lessons from Japan -- Separating Economic Growth from Energy Demand (London: Association for the Conservation of Energy, Spring 1990).

5. Higher efficiency need not necessarily be correlated with higher first cost. Thus, a survey of new refrigerators and freezers in Sweden indicates little correlation between energy performance and first cost (cf. Figure 222 on page 116 in J. Goldemberg et al., Energy for $a$ Sustainable World (Delhi: Wiley-Eastem Ltd., 1988). In fact, because the thrust of technological innovation is to achieve several design objectives simultaneously (cf. "Berg's theorem" in section 10.1), it can happen that an innovation reduces energy consumption along with a reduction in capital cost. In such cases, increased efficiency can go with a decreased first cost. For example, gas-turbine cogeneration systems are more energy efficient and less capitalintensive than steam-turbine cogeneration systems.

6. The approximation is valid for high discount rates and for savings measures that do not require extra operating costs.

7. H. Harvey and B. Keeping, Energy from Crisis to Solution (The Energy Foundation: Toward a sustainable future, 1990).

8. Of course, if the savings pay back the initial investment in an abnormally short time (say, a month or two), the sacrifice of current consumption is likely to be made.

9. B. Sudhakara Reddy, "The Energy Sector of the Metropolis of Bangalore," Ph.D. diss. submission, Indian Institute of Science, July 1990.

A.K.N. Reddy and B. Sudhakara Reddy, Substitution of Energy Carriers for Cooking and Waterheating -- a Case Study of the Domestic Sector of the Metropolis of Bangalore (in course of publication).

10. F. von Hippel and B.G. Levi, "Automotive Fuel Efficiency: The Opportunity and Weakness of Existing Market Incentives," Resources and Conservation, 10, 1983, pp.103-124.

11. Rationing can also have the opposite effect of encouraging energy inefficiency. If ration quotas are based on past consumption of energy, the energy-inefficient manager will have more leeway to reduce consumption during rationing periods than would an energy-efficient manager. Further, a plant manager may be inhibited from investing in energy efficiency for fear of being given a lower ration quota. 
12. H. Harvey and B. Keepin, op cit, Ref. 7.

13. "Manufacturers design most new products with the objective that these products will automatically be accepted by consumers through normal market mechanisms. Today, they seldom think much about energy efficiency when innovating. If manufacturers believed energy efficiency will be important to consumers or to society over the long term, they would routinely incorporate energy-efficiency features into new products (this has always been the case in the primary materials-processing industries), without the assistance of special promotional energyefficiency programs. This objective might be accomplished in part with taxes on externalities (e.g., carbon tax, oil tariff, pollutant effluent taxes, etc.). Performance regulations with long time horizons might also be effective in this regard, where applicable (e.g., consumer appliance efficiency standards that are established as continually improving targets over a long period of, say, 10-15 years." (cf. R.H. Williams, "Innovative approaches to Marketing Electric Efficiency," in T.B. Johansson, B. Bodlund and R.H. Williams (eds), Electricity: Efficient Enduse and Generation Technologies and their Planning Implications (Lund University Press, 1989), pp. 831-862.

14. J.W. Rowe, "Making Conservation pay: The NEES Experience," The Electricity Journal, December 1990, pp. 18-25.

15. According to Stephen Weiel (S. Weiel, "Making Electric Efficiency Profitable," Public Utilities Fortnightly, July 6, 1989) a typical electricity rate-making formula in the U.S. runs thus:

$$
R=O+\{(V-D) \cdot r\}+P
$$

where $\mathbf{R}$ is the revenue, 0 , the recovery of expenses (i.e., the operating costs or expenses in a test year including taxes), $\mathrm{V}$, the value of tangible and intangible property, $\mathrm{D}$, the accrued depreciation, $r$, the rate of return, $\{(V-D) . r\}$, the return on investment, $P$, the profit from services and $(R-P)$, the revenue requirements for setting rates.

16. D. Moskovitz, Profits and Progress through Least-Cost Planning, Report prepared by the National Association of Regulatory Utility Commissioners (Washington, D.C.: National Association of Regulatory Utility Commissioners, November 1989).

17. This is the case with electricity in the state of Karnataka, South India, where Karnataka Power Corporation Ltd. is responsible for generation and Karnataka Electricity Board for distribution. There are, however, power cuts in Karnataka, so that if the energy consumed by a low-tariff customer is reduced by efficiency improvements and sold to a high-tariff customer, the distributor can increase its revenues. This idea seems to have originated from Ashok Gadgil.

18. D. Moskovitz, op cit, Ref. 16.

19. D. Moskovitz, op cit, Ref. 16.

20. E. Larson, J. Ogden and R.H. Williams, Steam-injected Gas-turbine Cogeneration for the Cane Sugar Industry, PU/CEES Report No. 217, Princeton University, September 1987. 
21. K.V. Prabhakara Rao and A.K.N. Reddy, "A Techno-economic Study of Cogeneration with Specific Reference to the Sugar Industry"' in B.R. Pai and M.S. Rama Prasad (eds), Power Generation through Renewable Sources of Energy' (New Dellhi: Tata McGraw-Hill Publishing Company Limited, 1990).

22. A.K.N. Reddy et al., "Comparative Costs of Electricity Conservation and Centralized and Decentralized Electricity Generation," Economic and Political Weekly, Vol. XXV, No. 22, June 2, 1990, pp. 1201-1216.

23. V.S. Naipaul, An Area of Darkness (New York: MacMillan, 1964).

24. A.K.N. Reddy and J. Goldemberg, "Energy for the Developing World," Scientific American, Vol. 263, No. 3, September 1990, pp. 110-118.

25. All these $\mathrm{pc}$ is ts have been demonstrated clearly by the least-cost planning exercise that has been carried out for the state of Karnataka, South India. The extra energy required by the state in the year 2000 (over and above the 1986 value) can be met to the extent of $54 \%$ from efficiency improvements, $25 \%$ from decentralized sources and only $21 \%$ from new centralized sources (A.K.N. Reddy et al., "A Development-focussed End-use-oriented Electricity Scenario for Kamataka," Economic and Political Weekly, to be published).

26. H.S. Geller and J.R. Moreira, Brazil's National Electricity Conservation Program (PROCEL): Progress and Lessons, Paper for discussion at the Rockefeller Foundation meeting to found a global energy-efficiency mechanism, Geneva, May 4-5, 1991.

27. According to Moskovitz, (op cit, Ref. 16), the disincentives against investments in efficiency improvemerits originate from a combination of accounting conventions, legal and procedural aspects such as regulatory lag, retroactive ratemaking and fuel adjustment clauses. The regulators can remove disincentives by decoupling profit irom sales, minimizing costs, keeping administration simple, switching fuels, counting environmental costs and monitoring nonparticipant impacts. Many mechanisms are available to regulators to achieve these objectives, including rate-of-return adjustments and sharing of savings and bounty (which is a payment to utilities in return for specified achievements, e.g., energy saved).

28. Oregon Public Utility Commission, Oregon Public Utility Commission News (Salem, Oregon: Oregon Public Utility Commission, July 19, 1990).

29. The charge for energy savings will be based on a customer's retail rate (i.e., $75 \%$ of rate which (i.e., $75 \%$ of a rate which may change from time to time or $90 \%$, which would remain fixed for the life of the contract) but will be significantly less than if the customer consumed additional electricity instead. The energy service charge will be a single line item on the customers monthly bill.

30. The "no losers" or price minimization test is satisfied when the cost of conservation is less than the difference between the retail electricity price and the utility's avoided cost. Thus, conservation expenditures beyond the "no losers" test would increase electricity rates. 
31. In a resolution approved in July 1989, the U.S. National Association of Regulatory Utility Commissioners concluded that regulatory reform was needed to remove the disincentives to least-cost planning and to make the successful implementation of a utility's least-cost plan its most profitable course of action (cf. D. Moskovitz, op cit, Ref. 16).

32. The phenomenon under discussion is not restricted to developing countries; the U.S. has one of the lowest prices of gasoline.

33. Advisors from industrialized countries who glibly recommend price reforms in developing countries should think for a moment of the political consequences of raising gasoline prices in the U.S.

34. It must be noted that this guideline of implementing efficiency improvements simultaneously with price increases runs counter to the usual dictum of the donor or aid agency which says "First, get your prices right, and then we will fund your efficiency improvements!"

35. This tendency to favour large projects is found at the national level also. Thus, the Power Secretary of the Government of India categorically rejected small-size power projects ("Don't come to me with $100 \mathrm{MW}$ projects!") and asked for projects of $250 \mathrm{MW}$ or larger (Times of India, August 19, 1990).

36. D. Bleviss, Energy Efficiency Standards for Developing Countries: Issues to Consider, Paper for discussion at the Rockefeller Foundation meeting to found a global energy-efficiency mechanism, Geneva, May 4-5, 1991.

37. C.A. Berg, Energy Conservation in Industry: the Present Approach, the Future Opportunities (Washington, D.C.: President's Council on Environmental Quality, 1979).

38. To quote Robert Williams (personal communication, December 15, 1990): "This means that the "no-losers test" must be satisfied in large-scale programs. For small, embryonic programs it is not so important, because as long as investments in energy efficiency account for only a tiny fraction of total energy services provided, rates will not be much affected by subsidizing energy efficiency, so that non-participants are not burdened by rates that have to be raised to pay for conservation programs. Subsidies will often be desirable initially, to reward those with the courage to 'go first.' But for programs that seek to capture the full economic potential of efficiency improvement, it is important to try to satisfy the no-losers test. Example: Suppose an innovative entrepreneur builds a super energy-efficient, modern factor that produces highquality widgets at competitive cost in the service territory of a utility that is subsidizing energyefficiency investments in the factories of his economically inefficient competitors, to the extent that rates go up and the entrepreneur loses his competitive edge. Is it equitable that the entreprneur should be penalized with higher electrical rates to subsidize energy-efficiency investments at the factories of his inefficient competitors?"

39. Energy service company contracts will usually be based on estimated savings.

40. A.K.N. Reddy, "A Strategy for Resolving India's Oil Crisis," Current Science, No. 50, 1981, pp. 50-53. 
41. H. Harvey and B. Keeping, op cit, Ref. 7.

42. John Wakeham, Energy Secretary of the United Kingdom holds a contrary view: "The financial benefits of saving energy are clear enough not to require additional government assistance ("Financial Times Survey on Energy Efficiency," Financial Times, section 4, p. 1, December 14, 1990), but the U.K. has had far less success than, for instance, Japan where the market was supplemented with financial incentives, information, regulations and standards, education and training of energy managers.

43. K. Yokobori, Aiming for Sustainable Development: Implications for Energy Policies and Strategies in Developing Countries, Proceedings of Petrad Seminar on the Role of Petroleum in Sustainable Development, Penang, Malaysia, January 7-11, 1991 (in course of publication).

44. Incidentally, research and development have been a major component of Japanese energy policy. Japan has a Sunshine Project for alternative energy sources (coal liquefaction and gasification, solar and geothermal energy and "seed technologies" such as ocean thermal energy conservation, wind energy and biomass) and a Moonlight Project for energy conservation technologies (advanced battery storage systems, fuel cells, heat pumps, superconductivity, ceramic gas turbines and energy conservation in furnaces, boilers, generators and other industrial plants). The budget of the Sunshine Project is four times the budget of the Moonlight project - and 10 times the total research budget of the U.K.'s Department of Eriergy! 

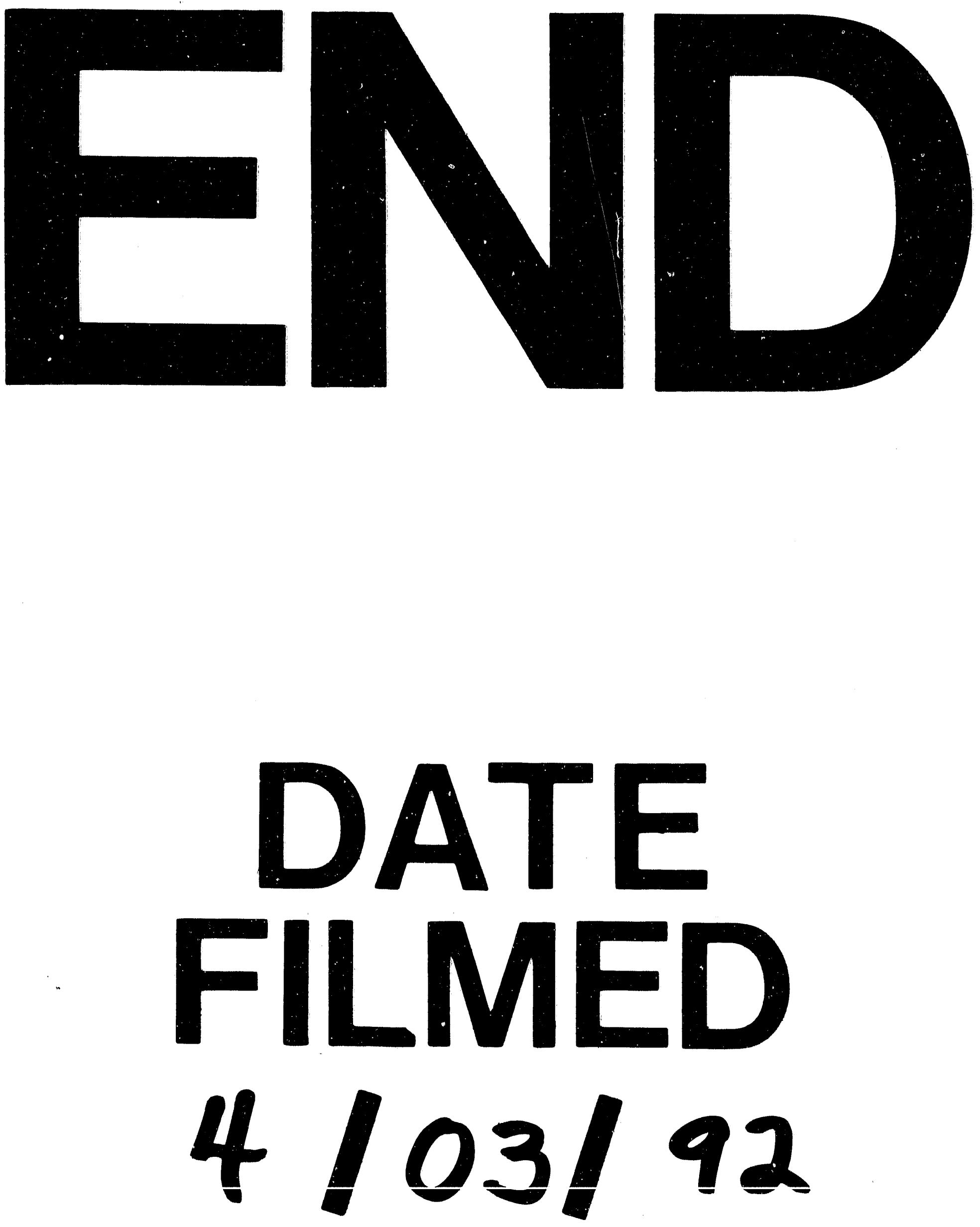
